Tema: Engenharia de superfície

\title{
ANÁLISE DO PARÂMETRO DE REDE E DA QUANTIDADE DE FASE S PRODUZIDA POR NITRETAÇÃO A PLASMA DE PÓS DE AÇO INOXIDÁVEL AUSTENÍTICO AISI 316*
}

\author{
Luciano Gianizeli Rodrigues ${ }^{1}$ \\ Lorena Bertranda ${ }^{2}$ \\ Adonias Ribeiro Franco Júnior ${ }^{3}$
}

Resumo

Este trabalho estuda a obtenção da fase $S$ livre de precipitados, a partir da nitretação a plasma de pós de aço inoxidável austenítico 316, e analisa a variação do parâmetro de rede (as) em função das diferentes condições de tempo e temperatura de tratamento. Os pós com granulometria entre 38 e $54 \mu \mathrm{m}$ foram nitretados em reator a plasma pulsado DC, sob atmosferas de $80 \% \mathrm{~N}_{2}$ e $20 \% \mathrm{H}_{2}$, pressões de $400 \mathrm{~Pa}$, por tempos de 1 a $9 \mathrm{~h}$, e temperaturas de 420,450 e 470ㄷ․ Os resultados mostram que para a temperatura de $420^{\circ} \mathrm{C}$ o parâmetro de rede (as) aumenta continuamente com o tempo de tratamento, atingindo a máxima expansão $(8,5 \%)$. Com o aumento da temperatura e do tempo de tratamento, verificou-se um recuo em as associado à perda de nitrogênio e conseqüente formação de nitretos. É possível obter na temperatura $420^{\circ} \mathrm{C}$ após $9 \mathrm{~h}$ cerca de $37 \%$ de fase $S$ livre de precipitados, o que mostra a necessidade de realização de experimentos adicionais ou do desenvolvimento de métodos de separação das partículas nitretadas das não nitretadas.

Palavras-chave: Aço inoxidável austenítico AISI 316; Fase S; Parâmetro de rede; Nitretação a plasma.

\section{ANALYSIS OF THE LATTICE PARAMETER AND AMOUNT OF S-PHASE PRODUCED BY PLASMA NITRIDING OF AISI 316 AUSTENITIC STAINLESS STEEL POWDERS}

\begin{abstract}
This work deals with studies on the production of $S$ phase from 316 steel powders. Powder particles with size between 38 and $54 \mu \mathrm{m}$ were plasma nitrided in a pulsed DC plasma nitriding unit, using gas atmosphere of $80 \% \mathrm{~N}_{2}+20 \% \mathrm{H}_{2}$, under $400 \mathrm{~Pa}$, at temperatures of 420,450 e $470^{\circ} \mathrm{C}$ and different times. The results show that at $420^{\circ} \mathrm{C}$ after $9 \mathrm{~h}$ the lattice parameter increases with the nitriding time, reaching the maximum expansion of $8.5 \%$ due to an introduction of $39.7 \%$ of nitrogen. At higher temperatures, increasing in the nitriding times led to a reduction in the lattice parameter due to nitrogen depletion from the $S$ phase and the formation of nitride. At $420^{\circ} \mathrm{C}$ after $9 \mathrm{~h}$, approximately $37 \%$ of $S$ phase was possible to be produced, demonstrating the need to conduct new investigations, or to develop a method for separating the untreatead from the nitrided particles.

Keywords: AISI 316 austenitic stainless steel; S phase; Lattice parameter; Plasma nitriding.

1 Engenheiro metalurgista, Mestre em Engenharia Metalúrgica e de Materiais, PROPEMM, IFES, campus Vitória, Vitória, ES, Brasil.

2 Tecnóloga em Siderurgia, Mestranda em Engenharia Metalúrgica e de Materiais, PROPEMM, IFES, campus Vitória, Vitória, ES, Brasil.

3 Engenheiro Metalurgista, Doutor em Engenharia Metalúrgica, Professor Doutor, Programa de Pós Graduação em Engenharia Metalúrgica e de Materiais (PROPEMM), IFES, campus Vitória, Vitória, ES, Brasil.
\end{abstract}

\footnotetext{
* Contribuição técnica ao1 ${ }^{\circ}$ Workshop de tratamentos de superfícies de ligas resistentes à corrosão,21 a 25 de julho de 2014, São Paulo, SP, Brasil.
} 


\section{INTRODUÇÃO}

Diferentes fases de nitreto de ferro podem ser obtidas a partir de partículas de pó de $\mathrm{Fe}-\alpha$ por uma rota envolvendo nitretação convencional e recozimento [1-3]. Bezdička et al. $[1,2]$ mostram que com a otimização das condições de processamento é possível produzir até $60 \%$ de $\mathrm{Fe}_{16} \mathrm{~N}_{2}$ - $\mathrm{\alpha}$ ". Outra rota para a produção de nitretos de ferro consiste na moagem de alta energia dos pós em atmosfera contendo nitrogênio $[4,5]$. De acordo com Coey e Smith [6], os nitretos $\mathrm{Fe}_{16} \mathrm{~N}_{2}-\mathrm{a}^{\prime \prime}$ e $\mathrm{Fe}_{4} \mathrm{~N}-\gamma^{\prime}$ possuem interessantes propriedades magnéticas, permitindo suas aplicações em ímãs permanentes e como materiais para uso em gravação magnética. Outros estudos mostram a possibilidade de produção de componentes a partir de pós de $\mathrm{Fe}-\gamma$ por uma rota que consiste de uma etapa de compactação seguida por outras de sinterização em atmosfera $\mathrm{N}_{2}-\mathrm{H}_{2}$ ou $\mathrm{NH}_{3}$ (ou por nitretação a plasma) e de tratamentos térmicos de recozimento e envelhecimento [7,8].

Conforme pode-se concluir da ref. [9], até a presente data na literatura não foram publicados estudos relativos à nitretação a plasma de pós (soltos) de aço austenítico $(\mathrm{Fe}-\gamma)$, em contraste com uma série deles que trata da nitretação da superfície de peças ou componetes (bulk).

Atualmente a maior parte das pesquisas relacionadas à nitretação do aço inoxidável 316 ainda está focada no aumento da sua resistência ao desgaste [10-14]. As melhorias na resistência ao desgaste são atribuídas à formação de uma camada fina constituída de fase $\mathrm{S}$, também denominada austenite expandida, que tem um parâmetro de rede (as) até $9,5 \%$ maior do que o da austenita $\left(\mathrm{a}_{\gamma}\right)$, devido à supersaturação da mesma com átomos intersticiais de nitrogênio [15-18].

Os principais métodos que permitem obter camadas finas de fase $S$ na superfície de peças de aço inoxidável austenítico são nitretação a plasma DC, implantação iônica, nitretação if e processo $\mathrm{PI}^{3}[19,20]$. Nesses métodos, o bombardeio de espécies altamente reativas presentes no plasma promove uma diminuição na energia de ativação necessária para a difusão dos átomos de nitrogênio, o que resulta numa profundidade de nitretação bem maior. Na interação entre o plasma e a superfície do material, podem ocorrer fenômenos como aquecimento e geração de lacunas, o que facilita a difusão dos átomos de nitrogênio.

$\mathrm{O}$ esgotamento de cromo, quer da matriz austenítica quer da camada de fase $\mathrm{S}$, pode ser evitado quando utilizada uma temperatura de tratamento inferior à temperatura crítica de precipitação $[11,12]$ que depende do tempo de tratamento. De acordo com a curva potencial limite de precipitação de CrN de Li e Bell [11,12], para a nitretação a plasma do aço austenítico 316 , a $470^{\circ} \mathrm{C}$, por exemplo, tanto o nitreto de cromo ( $\mathrm{CrN})$ quanto as estruturas de morfologia acicular $\left(\mathrm{Fe}_{4} \mathrm{~N}-\gamma^{\prime}\right)$ começam a se formar na superfície do material após aproximadamente $3 \mathrm{~h}$ de tratamento.

O objetivo deste trabalho foi: (i) obter a fase $S$ livre de precipitados através da nitretação a plasma de pós de aço inoxidável austenítico 316 e (ii) analisar o comportamento do parâmetro de rede (as) em função da temperatura e do tempo de tratamento. Assim, ele constitui-se numa das primeiras tentativas de produzir em grandes quantidades pós de fase $\mathrm{S}$ a partir de pós de Fe- $\gamma$. Espera-se que num futuro próximo peças avançadas de fase $S$ sejam produzidas por meio de uma rota que envolva etapas de atomização, nitretação a plasma, compactação e sinterização. Com isso, a aplicação da fase $\mathrm{S}$, ainda restrita à superfície de componentes de aço austenítico, poderá ser expandida para o seu núcleo, estendendo ainda mais o seu âmbito de aplicação, incluindo materiais estruturais, ferramentas e próteses.

* Contribuição técnica ao $1^{\circ}$ Workshop de tratamentos de superfícies de ligas resistentes à corrosão,21 a 25 de julho de 2014, São Paulo, SP, Brasil. 


\section{MATERIAIS E MÉTODOS}

\subsection{Material}

O pó de austenita $(\mathrm{Fe}-\gamma)$ utilizado nesta pesquisa foi produzido por atomização pela empresa P / M Pós-Metálicos Especiais, Campinas-SP, Brasil. A Tabela 1 mostra que a composição química do material é correspondente a do aço inoxidável austenítico AISI 316L.

Tabela 1. Composição química do pó de aço inoxidável AISI 316 usado neste estudo.

\begin{tabular}{ccccccccc} 
Elemento & $\mathrm{C}$ & $\mathrm{Mn}$ & $\mathrm{Si}$ & $\mathrm{Cr}$ & $\mathrm{Ni}$ & $\mathrm{Mo}$ & $\mathrm{S}$ & $\mathrm{P}$ \\
\hline \% em peso & 0,073 & 1,83 & 0,98 & 16,00 & 13,93 & 2,57 & 0,029 & 0,035
\end{tabular}

Usando um equipamento de peneiramento vibratório, amostras do pó com uma distribuição granulométrica na faixa de 38 a $53 \mu \mathrm{m}$ foram separadas através da seleção das frações de pó que passaram pela peneira de abertura de 270 \# e daquelas que ficaram retidas na peneira de abertura de 400 \#.

\subsection{Nitretação}

Para cada experimento de nitretação foram usadas amostras de pó com massa aproximada de $1000 \mathrm{mg}$ e altura de cama medindo aproximadamente 1,0 mm. Em cada experimento, as amostras de pó foram nitretadas em cinco navículas de aço inoxidável 304 que possuíam área superficial total de aproximadamente $25,0 \mathrm{~cm}^{2}$.

Os experimentos foram realizados em equipamento de nitretação a plasma pulsado SDS Soluções mod Thor NP, pertencente ao Lab. de Engenharia de Superfícies do IFES, campus Vitória. Detalhes deste equipamento podem ser encontrados na ref. [21].

Antes do início da nitretação, as amostras de pó foram aquecidas usando uma taxa de aproximadamente $7^{\circ} \mathrm{C} / \mathrm{min}$ sob fluxo de hidrogênio até a temperatura desejada (420, 450 ou $\left.470^{\circ} \mathrm{C}\right)$. Simultaneamente ao aquecimento da cama de pó, a limpeza superficial foi realizada por "sputtering" usando plasma de hidrogênio sob pressão de $100 \mathrm{~Pa}$, por cerca de 30 minutos. Após alcançar a temperatura de trabalho, o gás hidrogênio foi substituído pela mistura de $\mathrm{N}_{2}$ e $\mathrm{H}_{2}$, iniciando os experimentos de nitretação realizados sob pressão de $400 \pm 40 \mathrm{~Pa}$ por tempos de 1 a $9 \mathrm{~h}$. Foram utilizados fluxos de mistura gasosa de $400 \mathrm{~cm}^{3} / \mathrm{min}$, estritamente controlados por dois fluxímetros, um que permitia a entrada de $320 \mathrm{~cm}^{3} / \mathrm{min}$ de $\mathrm{H}_{2}$ ( $80 \%$ vol.) e outro de $80 \mathrm{~cm}^{3} / \mathrm{min}$ de $\mathrm{H}_{2}$ (20\% vol.). Ambos os gases, fornecidos pela White Martins, possuíam grau de pureza analítico (99,999\%). Após nitretação, o resfriamento das amostras, realizado no interior da câmara sob vácuo até temperatura ambiente, foi feito usando velocidade aproximada de $17^{\circ} \mathrm{C} / \mathrm{min}$, sob pressão de $10-100 \mathrm{~Pa}$.

\subsection{Gravimetria}

O nitrogênio introduzido na estrutura das amostras de pó (em \% em peso), determinado pelo ganho de massa das mesmas após nitretação, foi quantificado com o auxílio de uma balança semi-analítica de precisão de $\pm 0,1 \mathrm{mg}$.

As estimativas da fração de fase $S$ formada, bem como da profundidade de cama nitretada, foram feitas com base no nitrogênio introduzido, considerando aproximadamente plana a interface entre as regiões nitretadas e não nitretadas e

* Contribuição técnica ao1 ${ }^{\circ}$ Workshop de tratamentos de superfícies de ligas resistentes à corrosão,21 a 25 de julho de 2014, São Paulo, SP, Brasil. 
que na fase S estão dissilvidos em média $40 \%$ at. (cerca de $12 \%$ em peso) de nitrogênio.

\subsection{Difração de raios-x}

As análises das fases na estrutura dos pós nitretados foram realizadas em difratômetro de raio x modelo D2 Phaser Bruker, pertencente ao Laboratório de Caracterização do IFES - campus Vitória, operando com uma fonte de radiação de Cu K- $\alpha$. As amostras de pó para as análises possuíam massa entre 1000 e 1100 mg e foram utilizadas as seguintes condições de ensaio: tempo de contagem de $1 \mathrm{~s}$, com $2 \theta$ varrendo de 30 a $80^{\circ}$, passo de $0,02^{\circ}$ em $2 \theta$ e velocidade de rotação de 5 rpm. O parâmetro de rede da fase $S$ (as) para as diferentes condições de temperatura e tempo de nitretação foi estimado usando o método dos mínimos quadrados de Cohen [22] e o teor de nitrogênio na austenita expandida ( $N$ s) calculado a partir de relações empíricas com o parâmetro de rede da austenita $\mathrm{Fe}-\mathrm{N}$ [23].

\subsection{Microscopia Eletrônica de Varredura}

Aspectos morfológicos das partículas de pó, assim como a microestrutura das mesmas, foram caracterizados com o auxílio de um microscopio eletrônico de varredura (MEV) Philips XL - 30 pertencente ao laboratório de Microscopia Eletrônica e de Força Atômica do Departamento de Engenharia Metalúrgica e de Materiais da Escola Politécnica da USP, São Paulo-SP. Nas caracterizações morfológicas foram usadas partículas soltas do pó, enquanto nas caracterizações microestruturais, as partículas do pó foram embutidas a quente em baquelite. $O$ embutimento foi realizado misturando aproximadamente um quarto do pó a ser analisado com três quartos de baquelite em pó $(<90 \mu \mathrm{m})$. Na máquina de embutimento, antes da compactação, primeiro se fez uma cama consistindo de uma mistura de baquelite e de partículas do pó a analisar, e sobre essa mistura se adicionava somente baquelite. A preparação metalográfica envolveu o lixamento (em água) das amostras usando apenas as lixas (de SiC) de 600 e 1000 \#, o polimento com alumina de 0,3 $\mu \mathrm{m}$, o que permitiu o seccionamento tranversal de várias partículas e, por fim, o ataque químico com água régia $(75 \mathrm{ml}$ de $\mathrm{HCl}$ e $25 \mathrm{ml}$ de $\mathrm{HNO}_{3}$.

\section{RESULTADOS E DISCUSSÃO}

\subsection{Morfologia e Microestrutura das Partículas Antes da Nitretação}

A Figura 1 mostra aspectos morfológicos e microestruturais das partículas do pó de Fe- $\gamma$ antes da nitretação. Verifica-se na Figura 1(a) que as partículas atomizadas, tamanho médio entre 38-53 $\mu \mathrm{m}$, possuem um formato irregular que depende fortemente das condições de processamento (diâmetro do filete de metal, velocidade de resfriamento, entre outras) e de propriedades físicas e químicas do metal líquido [24]. É de se esperar que seja maior o aporte de nitrogênio atômico a se difundir da superfície para o interior dessas partículas, em razão das mesmas possuírem alta razão área/volume (maiores superfícies de reação) em relação a superfícies planas (de peças bulk) que possuem baixa razão área/volume. A estrutura das partículas de austenita é dendrítica conforme mostra a Figura 1(b).

* Contribuição técnica ao1Workshop de tratamentos de superfícies de ligas resistentes à corrosão,21 a 25 de julho de 2014, São Paulo, SP, Brasil. 

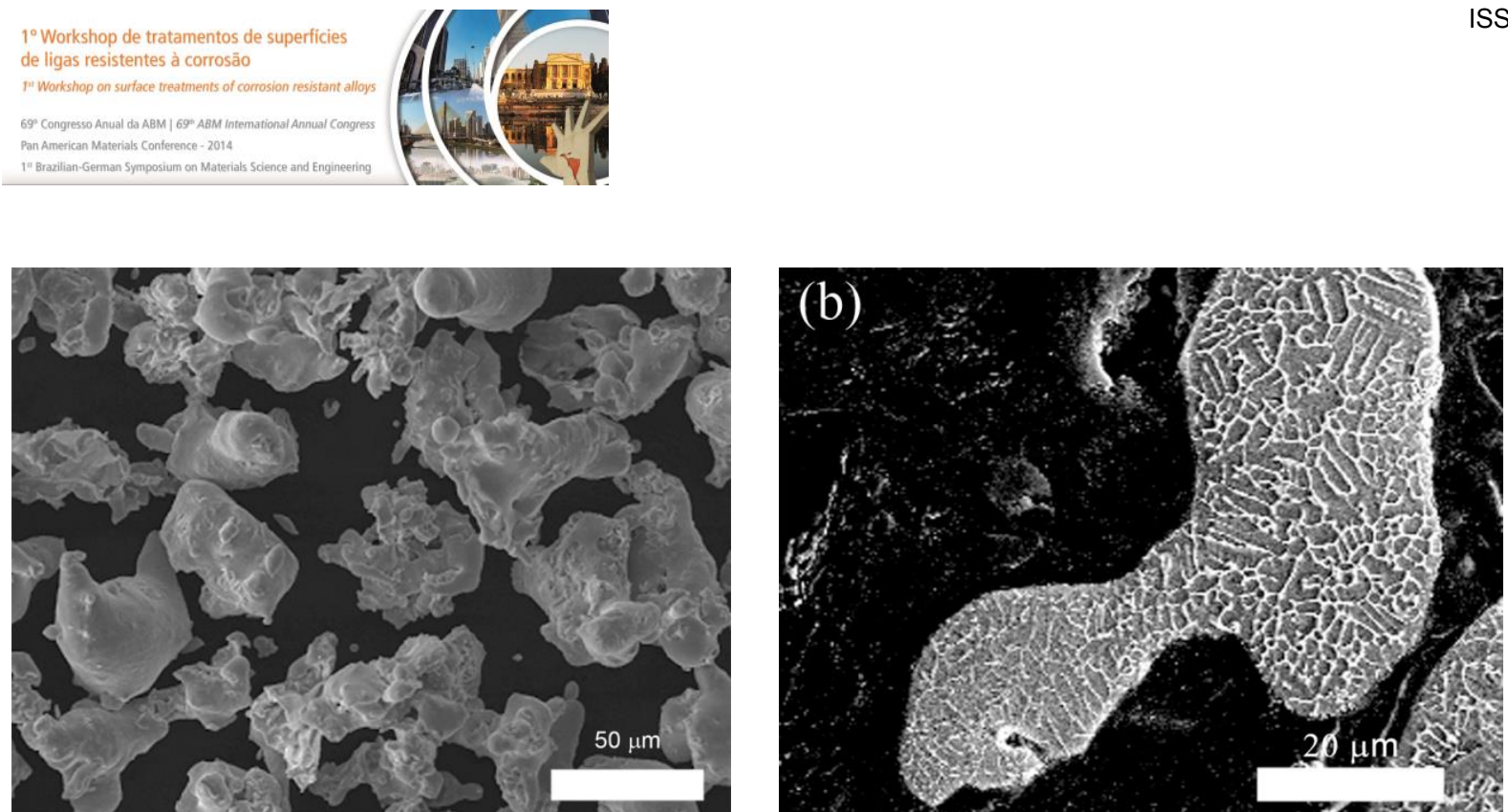

Figura 1. (a) Pó de aço 316 antes da nitretação e (b) seção transversal de uma partícula mostrando a sua estrutura dendrítica.

\subsection{Morfologia das partículas após nitretação}

A Figura 2 mostra detalhes microestruturais típicos do pó de aço inoxidável 316 após nitretação.
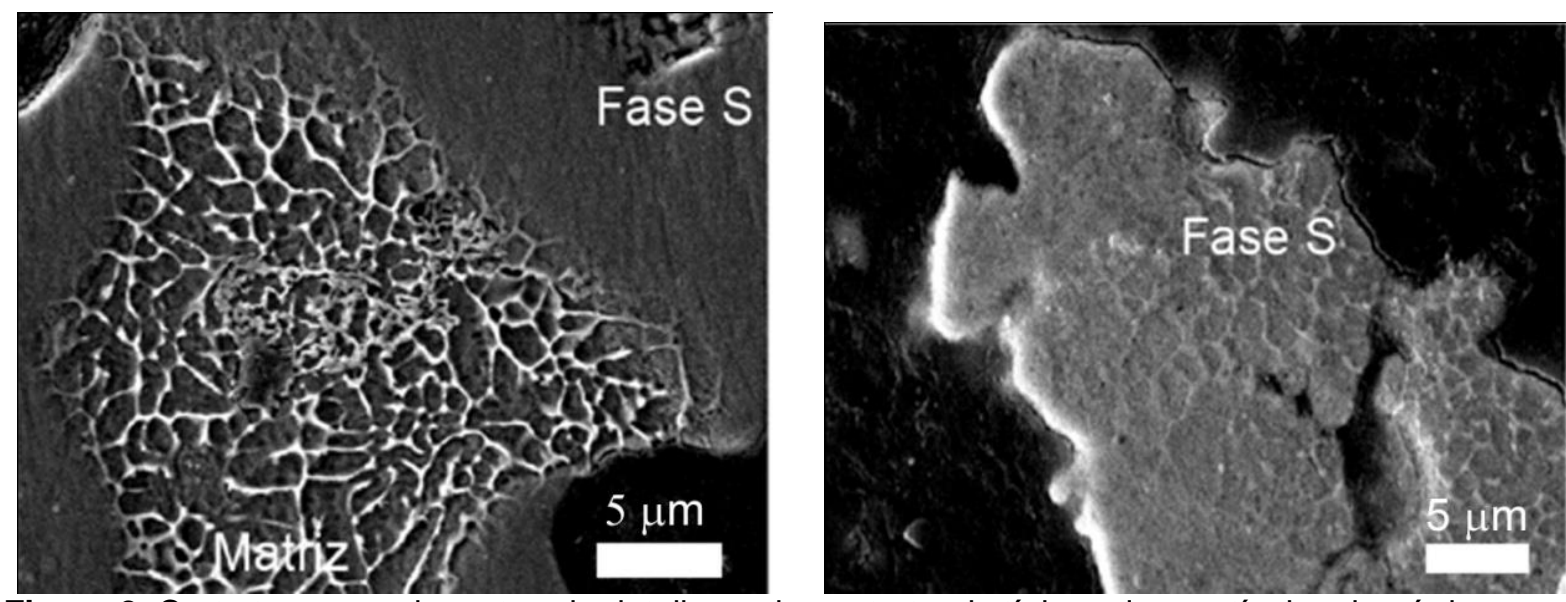

Figura 2. Corte transversal mostrando detalhes microestruturais típicos das partículas de pó do aço 316 após nitretação: (a) $1 \mathrm{~h} / 420^{\circ} \mathrm{C}$ e (b) $6 \mathrm{~h} / 470^{\circ} \mathrm{C}$.

O reagente químico (água régia) utilizado ataca fortemente os grãos das partículas de $\mathrm{Fe}-\gamma$, revelando a estrutura dendrítica das partículas do pó mostrada na Figura 1(b). Na Figura 2(a) nota-se que algumas partes da partícula do aço não foram atacadas, permanecendo em relevo, enquanto outra parte constituída de Fe- $\gamma$ foi totalmente revelada. Em razão disso, conclui-se que a porção não atacada se trata de uma fase diferente do Fe- $\gamma$. Com base no diagrama de Bell-Li [11-12], e de vários trabalhos de caracterização encontrados na literatura referentes à nitretação de peças (bulk) de aço inoxidável 316, pode-se concluir que a região não atacada corresponde à austenita expandida (ou fase $\mathrm{S}$ ).

A Figura 3 mostra esquematicamente a cama de pó de aço inoxidável após nitretação. Através de estimativas de profundidade média da cama de pó (h), a qual possuía profundidade média de $1,0 \mathrm{~mm}$, verificou-se que a região transformada $\left(\mathrm{h}_{\mathrm{s}}\right)$ pode chegar a 67\%. Esses resultados são apresentados na Seção adiante.

\footnotetext{
* Contribuição técnica ao1ํWorkshop de tratamentos de superfícies de ligas resistentes à corrosão,21 a 25 de julho de 2014, São Paulo, SP, Brasil.
} 


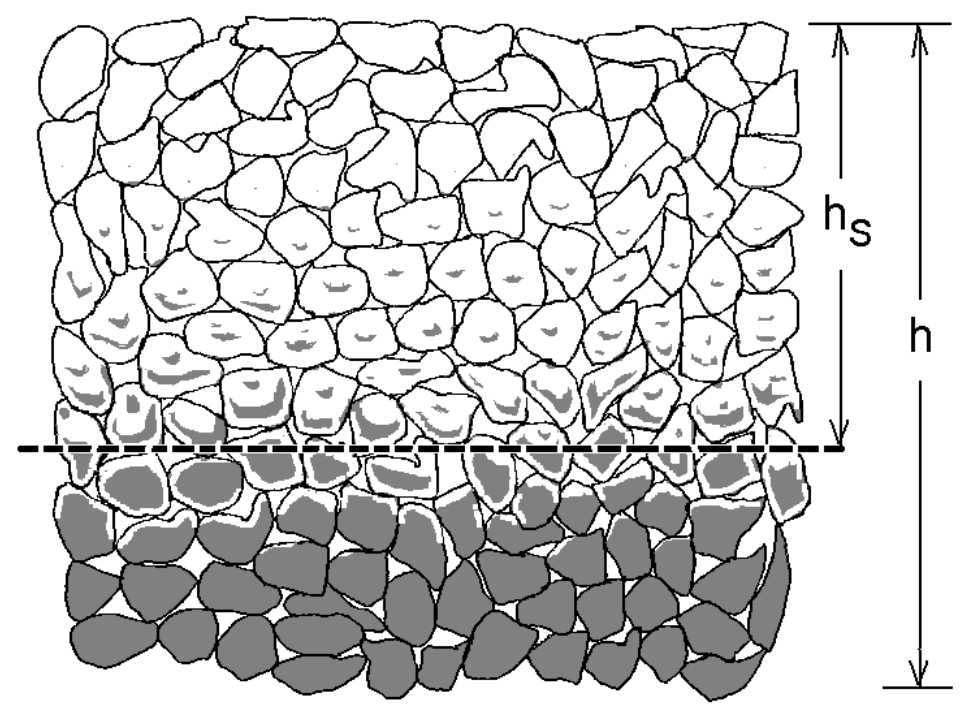

Figura 3. Representação esquemática da cama de pó após nitretação, onde: hs = profundidade média da cama de pó transformada em fase $S$ (ou fase $S+$ nitretos) e $h=$ profundidade total da cama de pó.

Para todas as condições de nitretação (temperaturas de 420,450 e $470^{\circ} \mathrm{C}$ por tempos de 1 a 9 h), verificou-se que após nitretação a cama de pó se constitui de partículas que apresentaram um dos três tipos de estrutura:

- não transformada, partícula possuindo apenas grãos da fase $\gamma$ atacados (Figura 1(b);

- parcialmente transformada, contendo Fe $\gamma+$ fase $S$, em diferentes proporções (Figura 2 (a)); e

- totalmente transformada, contendo apenas a fase $S$ ou fase $S+$ nitretos (Figura 2(b)).

\subsection{Parâmetro de Rede da Fase S}

A Figura 4 mostra a variação do parâmetro de rede e do nitrogênio contido na fase $S$ em função da temperatura e do tempo de nitretação. Há uma variação significativa tanto da quantidade de nitrogênio quanto do parâmetro de rede da fase $\mathrm{S}$ com a temperatura e o tempo de nitretação.

Para a nitretação a $420^{\circ} \mathrm{C}$, após uma hora de tratamento a quantidade de nitrogênio

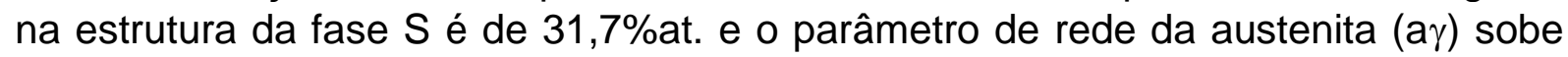
de $0,3584 \mathrm{~nm}$ para $0,3828 \mathrm{~nm}$, o que equivale a uma expansão de $6,8 \%$. Com o tempo de tratamento verifica-se um aumento progressivo da quantidade de nitrogênio na fase $S$ e, em conseqüência, no grau de expansão do parâmetro de rede da referida fase. Após $9 \mathrm{~h}$ de tratamento, a fase $\mathrm{S}$ possui aproximadamente $39,7 \%$ at. de nitrogênio e o seu parâmetro de rede está expandido em torno de $8,5 \%$. Pode-se concluir que na temperatura de $420^{\circ} \mathrm{C}$ após $9 \mathrm{~h}$ é possível a obtenção de fase $S$ livre de precipitados, já que não se detectou a presença de nitretos nem se verificou uma diminuição na quantidade de nitrogênio e conseqüente recuo do parâmetro de rede da referida fase.

Para a temperatura de $450^{\circ} \mathrm{C}$ observa-se que após $1 \mathrm{~h}$, a fase $\mathrm{S}$ formada possui aproximadamente $38,9 \%$ at. de nitrogênio, o que faz o seu parâmetro de rede se expandir em aproximadamente 8,3\%. Para $6 \mathrm{~h}$ de tratamento, verifica-se um pequeno recuo em as, que caiu de $0,3888 \mathrm{~nm}(3 \mathrm{~h})$ para as $=0,3878 \mathrm{~nm}(6 \mathrm{~h})$; no entanto, das análises de difração não se constatou a presença de outras fase além

* Contribuição técnica ao1 ${ }^{\circ}$ Workshop de tratamentos de superfícies de ligas resistentes à corrosão,21 a 25 de julho de 2014, São Paulo, SP, Brasil. 
do Fe- $\gamma$ e da fase S. Para o tempo de tratamento de $9 \mathrm{~h}$, o nitrogênio introduzido foi de $36,6 \%$ at. e o parâmetro de rede retraiu para $0,3865 \mathrm{~nm}$. A difração de raio $\mathrm{x}$ evidenciou nos pós a presença não só da fase $\mathrm{S}$ e do Fe- $\gamma$, mas também de picos de baixa intensidade. No entanto, após tratamentos realizados por $9 \mathrm{~h}$ a presença de nitreto não é prevista no diagrama Bell-Li [13] onde é indicado que o início da precipitação de CrN ocorre somente a partir de $12 \mathrm{~h}$ de tratamento.

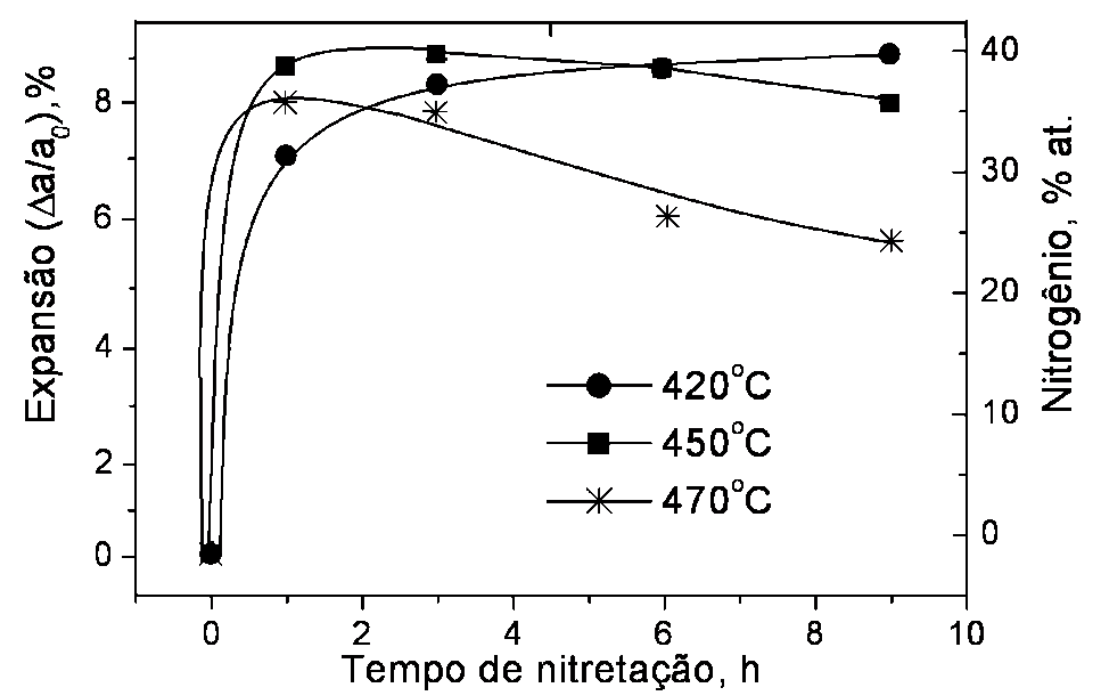

Figura 4. Variação do parâmetro de rede $\left(\Delta \mathrm{a} / \mathrm{a}_{\circ}\right)$ e da quantidade de nitrogênio (\% at.) da fase $S$ com o tempo e a temperatura de nitretação.

Com o aumento da temperatura para $470^{\circ} \mathrm{C}$, após $1 \mathrm{~h}$ de tratamento o nitrogênio introduzido foi de 35,7\%at. e a expansão de reticulado correspondente de $7,7 \%$, conforme mostrado na Figura 4. Apesar do recuo do parâmetro de rede da fase $S$, não ficou evidenciada a formação de outras fases além do $\mathrm{Fe}-\gamma$ e da fase $S$ no difratograma de DRX correspondente. Verificou-se que acréscimos no tempo de tratamento promoveram uma forte queda no parâmetro de rede: $3 \mathrm{~h}(0,3835 \mathrm{~nm}), 6 \mathrm{~h}$ $(0,3785 \mathrm{~nm})$ e $9 \mathrm{~h}(0,3769)$. Após $9 \mathrm{~h}$, a expansão foi de apenas 5,2\% e o nitrogênio introduzido de $24,1 \%$. Portanto, a retração do parâmetro de rede da fase $S$ associada ao esgotamento de cromo e nitrogênio da estrutura da mesma ocorre em tempos bem mais curtos. Acima de $3 \mathrm{~h}$, as análises de DRX evidenciaram claramente a presença de $\mathrm{CrN}$ e de $\mathrm{Fe}_{4} \mathrm{~N}$ juntamente com a de $\mathrm{Fe}-\gamma$ e fase $\mathrm{S}$.

\subsection{Quantidade de Fase S Formada}

A Figura 5 mostra a variação da quantidade de nitrogênio e de austenita transformada na cama de pó de aço inoxidável 316 em função da temperatura e do tempo de nitretação. Constata-se que tanto a temperatura quanto o tempo de nitretação são variáveis que exercem uma forte influência na quantidade de nitrogênio que pode ser introduzida na estrutura das partículas de pó e, em conseqüência, na quantidade de fase $S$ formada. As diferentes condições empregadas permitiram a introdução de quantidades de nitrogênio que variaram de $0,94 \%$ em peso $\left(420^{\circ} \mathrm{C}, 1 \mathrm{~h}\right)$ a $7,68 \%$ em peso $\left(470^{\circ} \mathrm{C}, 9 \mathrm{~h}\right)$.

$\mathrm{Na}$ temperatura de $420^{\circ} \mathrm{C}$, por exemplo, com $1 \mathrm{~h}$ obtém-se um valor de $\mathrm{N}$ de $0,94 \%$ (8,0\% de fase S) e após $3 \mathrm{~h}$ esse valor praticamente dobra (16,0\% de fase $\mathrm{S})$. Valores de $\mathrm{N}$ em torno de 4,45\% (37\% de fase S) podem ser obtidos após $9 \mathrm{~h}$.

* Contribuição técnica ao1ํㅡorkshop de tratamentos de superfícies de ligas resistentes à corrosão,21 a 25 de julho de 2014, São Paulo, SP, Brasil. 


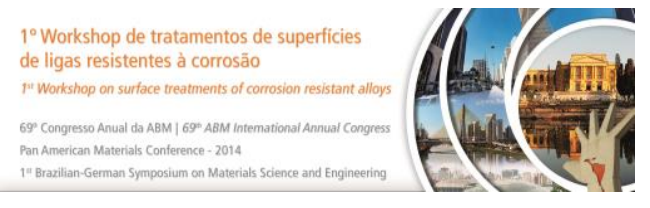

Portanto, nessa temperatura ocorre um aumento lento, mas progressivo do nitrogênio introduzido na estrutura dos pós com o tempo de nitretação. As análises de DRX confirmam a coexistência de fase $\mathrm{S}$ e Fe- $\gamma$ para todos os intervalos de tempo estudados.

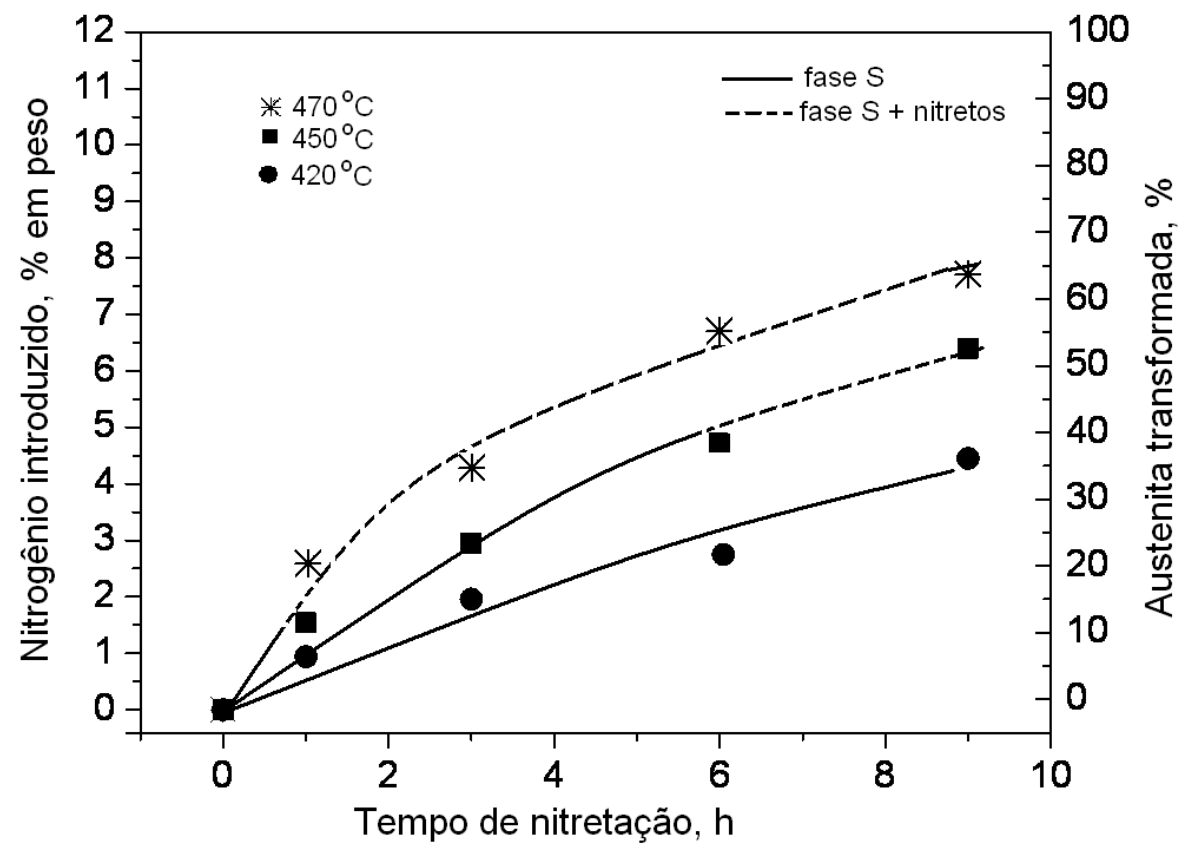

Figura 5. Variação (\%) do nitrogênio introduzido na cama de pó de aço 316 e da quantidade relativa de fase S (\%) em função do tempo e da temperatura de nitretação.

Para a temperatura de $450^{\circ} \mathrm{C}$, após $3 \mathrm{~h}$ obtém-se uma quantidade de nitrogênio aproximada de $2,95 \%$ ( $25 \%$ de fase S). Para 6 h de tratamento, conforme mostrado na Figura 4 ocorreu um pequeno recuo em as, que caiu de 0,3888 nm (após $3 \mathrm{~h}$ de nitretação) para as=0,3878 nm (após $6 \mathrm{~h}$ ); no entanto, nas análises de difração não se constatou a presença de outras fase além do Fe- $\gamma$ e da fase S. É possível obter $53 \%$ de austenita transformada $(\mathrm{N}=6,40 \%)$ após $9 \mathrm{~h}$ de nitretação. Nessa condição, as análises DRX evidenciaram nos pós a presença não só da fase $\mathrm{S}$ e do $\mathrm{Fe}-\gamma$, mas também de picos de baixa intensidade que denotam a presença de nitreto.

Aumentando a temperatura de $420^{\circ} \mathrm{C}$ para $470^{\circ} \mathrm{C}$, com apenas $1 \mathrm{~h}$ de nitretação já se consegue introduzir uma quantidade de nitrogênio equivalente a conseguida por 6 h na temperatura de $420^{\circ} \mathrm{C}$ conforme se infere da Figura 5 . Valores para $\mathrm{N}$ de $7,68 \%$ (64\% de austenita transformada) podem ser obtidos com o aumento do tempo de nitretação para $9 \mathrm{~h}$. Após $9 \mathrm{~h}$ de nitretação na temperatura de $470^{\circ} \mathrm{C}$, cerca de $64 \%$ da cama de pó se constitui de austenita transformada, restando portanto ainda $36 \%$ de Fe- $\gamma$. Para a amostra nitretada por $9 \mathrm{~h}$, das análises de DRX verificou-se que 0 pico S2 possui uma intensidade relativa maior que a do $\mathrm{Fe}-\gamma$ (200), o que confirma as estimativas feitas a partir dos dados de gravimetria as quais apontaram quantidades relativas de austenita transformada (fase $S+$ nitretos) maiores que as de Fe- $\gamma$.

\footnotetext{
* Contribuição técnica ao1 ${ }^{\circ}$ Workshop de tratamentos de superfícies de ligas resistentes à corrosão,21 a 25 de julho de 2014, São Paulo, SP, Brasil.
} 


\section{CONCLUSÃO}

- A nitretação a plasma em baixas temperaturas permite a obtenção de grandes proporções de fase $S$ a partir de pós de aço inoxidável austenítico 316 , podendo se constituir futuramente numa das etapas de um novo processo de produção de peças compostas exclusivamente pela referida fase.

- É possível obter até $37 \%$ de fase $S$ isenta de precipitados quando os tratamentos são realizados por cerca de $9 \mathrm{~h}$ na temperatura de $420^{\circ} \mathrm{C}$. Para maximizar a quantidade de fase $\mathrm{S}$, no entanto, é recomendado: (i) a realização de experimentos adicionais variando as principais condições de nitretação (por exemplo: uso de menores temperaturas e maiores tempos, adição de metano ou argônio na atmosfera de nitretação), (ii) o desenvolvimento de métodos de separação das partículas nitretadas das não nitretadas, e (iii) a implementação de sistemas de vibração da cama de pó para nitretar as partículas localizadas no fundo da navícula.

- O teor máximo de nitrogênio introduzido na fase $S$ é de $39,7 \%$ at., o que promove uma expansão de 8,5\% no parâmetro de rede.

\section{Agradecimentos}

Os autores agradecem a Ricardo Salvador Boldrini, Laboratório de Caracterização de Materiais do IFES, campus Vitória, ES, pelas análises DRX e ao Prof. Dr. André Paulo Tschiptschin, laboratório de Microscopia Eletrônica e de Força Atômica do Departamento de Engenharia Metalúrgica e de Materiais da Escola Politécnica da USP São Paulo-SP, pelas imagens de MEV. Em particular, o primeiro autor agradece à Fundação de Amparo à Pesquisa do Espírito Santo, FAPES, pela bolsa de mestrado concedida.

\section{REFERÊNCIAS}

1 Bezdička P, Kláriková A, Paseka I, Závěta K. Magnetic properties of $\alpha^{\prime}-F e N_{x}$ and $\alpha$ "- $\mathrm{Fe}_{16} \mathrm{~N}_{2}$ nitrides. Journal of Alloys and Compounds. 1998;274(1):10-17.

2 Paseka I, Bezdička P, Kláriková A, Závěta K. Structure and magnetic properties of ball-milled iron nitride powders. Journal of Alloys and Compounds. 1998;74(1):248-253.

3 Malinov S, Böttger AJ, Mittemeijer EJ, Pekelharing MI, Somers MA. Phase transformations and phase equilibria in the $\mathrm{Fe}-\mathrm{N}$ system at temperatures below 573 K. Metallurgical and Materials Transactions A. 2001;32(1):59-73.

4 Chen Y, Halstead T, Williams JS. Influence of milling temperature and atmosphere on the synthesis of iron nitrides by ball milling. Materials Science and Engineering: A. 1996;206(1):24-29.

5 Chen Y, Williams JS. High-energy ball-milling-induced non-equilibrium phase transformations. Materials Science and Engineering: A. 1997;226:38-42.

6 Coey JMD, Smith PAI. Magnetic nitrides. Journal of Magnetism and Magnetic Materials. 1999;200(1):405-424.

7 Bacci T, Borgioli F, Galvanetto E, Pradelli G. Glow-discharge nitriding of sintered stainless steels. Surface and Coatings Technology. 2001;139(2):251-256.

\footnotetext{
* Contribuição técnica ao1ํWorkshop de tratamentos de superfícies de ligas resistentes à corrosão,21 a 25 de julho de 2014, São Paulo, SP, Brasil.
} 
8 García C, Martín F, Tiedra P, Cambronero LG. Pitting corrosion behaviour of PM austenitic stainless steels sintered in nitrogen-hydrogen atmosphere. Corrosion science. 2007;49(4):1718-1736.

9 Dong $\mathrm{H}$. S-phase surface engineering of $\mathrm{Fe}-\mathrm{Cr}, \mathrm{Co}-\mathrm{Cr}$ and $\mathrm{Ni}-\mathrm{Cr}$ alloys. International Materials Reviews. 2010;55(2):65-98.

10 Zhang ZL, Bell T. Structure and corrosion resistance of plasma nitrided stainless steel. Surface Engineering. 1985;1(2):131-136.

11 Bell T. Surface engineering of austenitic stainless steel. Surface engineering. 2002;18(6):415-421.

12 Bell T, Li CX. Stainless steel low temperature nitriding and carburizing. Advanced Materials \& Processes. 2002;160(6):49-51.

13 Blawert C, Weisheit A, Mordike BL, Knoop FM. Plasma immersion ion implantation of stainless steel: austenitic stainless steel in comparison to austenitic-ferritic stainless steel. Surface and Coatings Technology. 1996;85(1):15-27.

14 Blawert C, Mordike BL, Jirásková Y, Schneeweiss O. Structure and composition of expanded austenite produced by nitrogen plasma immersion ion implantation of stainless steels X6CrNiTi1810 and X2CrNiMoN2253. Surface and Coatings Technology. 1999;116:189-198.

15 Han KH, Song YK. Structure of freshly formed and low-temperature aged Fe-N austenites. Materials Science and Engineering: A. 1999;260(1):246-251.

16 Hannula SP, Nenonen P, Hirvonen JP. Surface structure and properties of ionnitrided austenitic stainless steels. Thin Solid Films. 1989;181(1):343-350.

17 Leyland A, Lewis DB, Stevensom PR, Matthews A. Low temperature plasma diffusion treatment of stainless steels for improved wear resistance. Surface and Coatings Technology. 1993;62(1):608-617.

18 Meletis EI, Yan S. Low pressure ion nitriding of AISI 304 austenitic stainless steel with an intensified glow discharge. Journal of Vacuum Science \& Technology A. 1993;11(1):25-33.

19 Fewell MP, Mitchell DRG, Priest JM, Short KT, Collins GA. The nature of expanded austenite. Surface and Coatings Technology. 2000;131(1):300-306.

20 Li XY. Low Temperature Plasma Nitriding of 316 Stainless Steel-Nature of S Phase and Its Thermal Stability. Surface Engineering. 2001;17(2):147-152.

21 Rodrigues LG. Cinética de formação da austenita expandida produzida por nitretação a plasma de pós de aço inoxidável austenítico AISI 316 [dissertação de mestrado]. Vitória: IFES; 2013.

22 Cullity BD. Elements of X-ray Diffraction. $2^{\underline{a}}$ ed. Addison-Wesley, Reading, MA; 1978.

23 Cheng L, Böttger A, Keijser TH, Mittemeijer EJ. Lattice parameters of ironcarbon and iron-nitrogen martensites and austenites. Scripta Metallurgica et Materialia. 1990;24(3):509-514.

24 Li R, Shi Y, Wang Z, Wang L, Liu J, Jiang W. Densification behavior of gas and water atomized 316L stainless steel powder during selective laser melting. Applied Surface Science. 2010;256(13):4350-4356.

\footnotetext{
* Contribuição técnica ao1 ${ }^{\circ}$ Workshop de tratamentos de superfícies de ligas resistentes à corrosão,21 a 25 de julho de 2014, São Paulo, SP, Brasil.
} 